\title{
Hydrothermal Synthesis of $\mathrm{PbO}_{2} / \mathrm{RGO}$ Nanocomposite for Electrocatalytic Degradation of Cationic Red X-GRL
}

\author{
Weidong Li, ${ }^{1,2}$ Huayun Yang, ${ }^{2}$ and Qi Liu ${ }^{3}$ \\ ${ }^{1}$ Qianjiang College, Hangzhou Normal University, Hangzhou 310036, China \\ ${ }^{2}$ Environmental College, Zhejiang University of Technology, Hangzhou 310032, China \\ ${ }^{3}$ College of Life and Environmental Sciences, Hangzhou Normal University, Hangzhou, China \\ Correspondence should be addressed to Weidong Li; lwd@hznu.edu.cn
}

Received 4 December 2016; Accepted 26 January 2017; Published 13 March 2017

Academic Editor: Philip D. Rack

Copyright (C) 2017 Weidong Li et al. This is an open access article distributed under the Creative Commons Attribution License, which permits unrestricted use, distribution, and reproduction in any medium, provided the original work is properly cited.

\begin{abstract}
$\mathrm{PbO}_{2}$ nanoparticles were prepared using a simple hydrothermal method with $\beta$ - $\mathrm{PbO}$ as precursor and ammonium peroxydisulfate as oxidant. During the hydrothermal condition with ammonium peroxydisulfate, the formed hydroxyl radical has played a key role in the oxidation of $\beta-\mathrm{PbO}$ to $\mathrm{PbO}_{2}$. The size of as-prepared $\mathrm{PbO}_{2}$ nanoparticles was in the range of 25-50 nm. Reduced graphene oxide (RGO) was successfully prepared by the simple reduction reaction of graphene oxide by sodium borohydride and the obtained RGO was then incorporated into the $\mathrm{PbO}_{2}$ nanoparticles. The surface of ITO electrode was modified with the as-prepared $\mathrm{PbO}_{2} / \mathrm{RGO}$ nanocomposite. The constructed $\mathrm{PbO}_{2} / \mathrm{RGO} / \mathrm{ITO}$ electrode was subsequently applied for the catalytic degradation of cationic red X-GRL which was an azo dye in wastewater. The effects of reaction time, applied current density, and initial concentration of dye on the color removal and COD removal were thoroughly investigated. All results demonstrated that the degradation performance of the electrode modified with $\mathrm{PbO}_{2} / \mathrm{RGO}$ nanocomposite was extremely excellent.
\end{abstract}

\section{Introduction}

A large amount of wastewater has been produced in the textile industry since the consumption of chemical dyes and water in the dye bleeding processes in high demand. Owing to plenty of organic matters in wastewater (i.e., high chemical oxygen demand (COD)) and the hard degradation, the effluents are difficult to deal with using conventional treatments, leading to the emerge of severe environmental problems [1]. Cathonic red X-GRL, a kind of azo dye, is widely applied in various industries including varnish, plastic, and textile. Unfortunately, X-GRL is hard to be degraded by conventional process [2]. With the increasing concern of environmental protection and more and more strict legislation, the wastewater produced from textile industry must be purified before the discharge. Recently, several techniques including wet air oxidation (WAO) [3-5], catalytic wet air oxidation (CWAO) [6] and electrochemical oxidation [7] have been employed for the treatment of the wastewater. Owing to the unaffordable cost resulted from the demand of long operation time with high oxygen pressure and temperature, the wide application of traditional WAO is extremely limited. As to CWAO, the harsh operating conditions can be alleviated [8], and certain problems such as the efficiency reduction and secondary pollution still exist.

In recent years, advanced electrochemical oxidation processes (AOPs) have received wide attention as an effective technique for the treatment of wastewater composed of undegradable and poisonous compounds. AOPs possess great many advantages such as high efficiency, environmental compatibility, and most importantly easy applicability to automation [9-11]. As to AOPs, the electrode materials are the most important part which decide the efficiency and economy [12]. Generally, considering the degradation performance for organic pollutants, the nonactive electrodes outperform the active ones [13]. For the degradation of azo dye using electrochemical oxidation, the performances of various anodes including active carbon fiber (ACF) [14], Pt [15], $\mathrm{PbO}_{2}$ [16], $\mathrm{SnO}_{2}$ [17], $\mathrm{RuO}_{2}$ [18], and diamond electrode $[19,20]$ were investigated in detail. Nevertheless, owing to the low current efficiency possibly resulted from limited electrode surface area, the dye removal performances 
obtained on these electrodes are not satisfactory. Therefore, the exploration of new novel electrodes with high performance for the degradation of wastewater is highly required.

For increasing the active surface area of the electrode, reducing the particle size of the electrode material is a very effective method since much higher specific surface area can be achieved with nanosized materials. However, nanoparticles are easy to agglomerate, which will result in electrochemical performance degradation. For the sake of retaining the high specific surface area, varieties of conductive materials, including conductive carbon materials and polymers and metal oxides, can be adopted as a substrate for the electrode composed of nanomaterial. Graphene, a twodimensional material with only one-atom-thick layer of carbon, has attracted worldwide attentions owing to various extraordinary properties such as ultrahigh surface area and unique conductivity. Therefore, graphene can be employed in electrode materials for enhancing the electrocatalytic activity [21-23].

In this study, the composite composed of nanosized $\mathrm{PbO}_{2}$ and graphene was firstly prepared to the best of our knowledge. The as-prepared nanocomposite was then applied in the modification of commercial electrode. The performance of the $\mathrm{PbO}_{2}$-graphene nanocomposite for the azo dye degradation was investigated. Cationic red X-GRL, a hardly biodegradable dye that was widely used in various industries such as plastic, textile, and varnish, has been employed as a model organic substance in wastewater.

\section{Experimental}

2.1. Chemicals and Materials. Ammonium peroxydisulfate, graphite powder (99.99\%) with the particle size of $45 \mu \mathrm{m}$, and orthogonal phase $\beta$-PbO were all obtained from SigmaAldrich and used as received. Industrial cationic red XGRL supplied by Jin-Jiang Chemical Dyestuff Co. Ltd. was extracted with methanol at $50^{\circ} \mathrm{C}$ in order to achieve a purity of $99.5 \%$. The obtained X-GRL with high purity was used as the model pollutant. Doubly distilled water was used in the entire experiments.

2.2. Preparation Graphene Oxide. A modified Hummers' method was employed for the preparation of graphite oxide powder from natural graphite powder [24]. The graphite oxide suspension with a yellow-brownish color was obtained by dispersing the as-prepared graphite oxide powder into doubly distilled water. Then the obtained graphite oxide suspension was sonicated under power of $150 \mathrm{~W}$ and frequency of $40 \mathrm{kHz}$ for $15 \mathrm{~min}$ to promote the exfoliation of graphite oxide into graphene oxide sheets. Finally, unexfoliated graphite oxide was removed by treating the suspension with centrifugation at $6000 \mathrm{rpm}$ for $30 \mathrm{~min}$.

2.3. Hydrothermal Synthesis of Nanosized $\mathrm{PbO}_{2}, 1 \mathrm{~g} \beta-\mathrm{PbO}$ was mixed to $200 \mathrm{~mL}$ distilled water and the mixture was sonicated for $30 \mathrm{~min}$ in order to obtain a homogeneous solution. Subsequently, $120 \mathrm{~mL}$ ammonium peroxydisulfate solution $(0.5 \mathrm{M})$ was mixed with the solution of $\beta-\mathrm{PbO}$ and the mixture was treated with ultrasound for $1 \mathrm{~h}$. Then the mixture was transferred to a Teflon lined autoclaves $(500 \mathrm{~mL})$ and heated at $120^{\circ} \mathrm{C}$ for $2 \mathrm{~h}$. After the reaction solution was cooled down, a dark brown powder was obtained through centrifugation at $7500 \mathrm{rpm}$ for $15 \mathrm{~min}$. Finally, the obtained precipitate was washed with water several times and dried in an oven at $70^{\circ} \mathrm{C}$ for $1 \mathrm{~h}$.

2.4. Preparation of $\mathrm{PbO}_{2} / \mathrm{RGO}$ Nanocomposite. $\mathrm{GO}(50 \mathrm{mg})$ was firstly dispersed into water $(50 \mathrm{~mL})$ with sonication for $1 \mathrm{~h}$. Then, nanosized $\mathrm{PbO}_{2}(0.5 \mathrm{~g})$ was added to the GO suspension with sonication for another $1 \mathrm{~h}$. After the formation of a homogenous dispersion, $10 \mathrm{~mL}$ of $\mathrm{NaBH}_{4}$ solution $(1 \mathrm{M})$ was quickly added to the solution and then heated at $80^{\circ} \mathrm{C}$ for $2 \mathrm{~h}$ under stirring. After cooling down, $\mathrm{PbO}_{2} / \mathrm{RGO}$ was collected by treating the reaction solution with centrifugation at $7500 \mathrm{rpm}$ for $15 \mathrm{~min}$.

2.5. Electrode Modification. ITO wafers were washed in acetone, ethanol, and DI water separately for $20 \mathrm{~min}$ with sonicating and rinsed with plenty of doubly distilled water and then dried under the atmosphere of $\mathrm{N}_{2}$. Subsequently, $1 \mathrm{~mL}$ of $\mathrm{PbO}_{2} / \mathrm{RGO}$ dispersion $(1 \mathrm{mg} / \mathrm{mL})$ was casted on the ITO surface and dried at room temperature and the modified electrode was denoted as $\mathrm{PbO}_{2} / \mathrm{RGO} / \mathrm{ITO}$.

2.6. Characterizations. Powder X-ray Diffraction (PXRD) patterns of as-prepared samples were measured on Philips powder diffractometer PW 3040/60 instrument with $\mathrm{Cu}$ $\mathrm{K} \alpha$ radiation $(\lambda=1.541 \AA)$. Morphological feature of the samples was obtained on a field emission scanning electron microscope (SEM, Hitachi-S4800). And the concentration of red X-GRL was measured by a UV-vis spectrophotometer (Techcomp 8500, China) at wavelength of $530 \mathrm{~nm}$.

\subsection{Electrocatalytic Degradation of Cationic Red X-GRL.} The electrocatalytic degradation of cationic red X-GRL was performed in a cylindrical stainless autoclave $(500 \mathrm{~mL})$ with stainless steel net as the cathode. The experiments started while the temperature of wastewater solution $(250 \mathrm{~mL})$ within the reactor reached the set value. During the entire course of the experiment, the wastewater was stirred with suitable stirring speed in order to guarantee the kinetically controlled reactions. And the current density was kept constant at the selected value and the applied voltage was slightly adjusted. Dye concentration was analyzed spectrophotometrically by measuring the absorbance of the remaining dye at maximum wavelength $530 \mathrm{~nm}$ on a UV-vis spectrophotometer. The COD was measured by the standard method (closed reflux/photometry) [25].

\section{Results and Discussion}

The lead oxide was converted to lead dioxide by the oxidation reaction using a strong oxidizing agent ammonium peroxydisulfate. The surface of $\mathrm{PbO}$ particles was firstly oxidized to $\mathrm{PbO}_{2}$ that was easily desorbed and the oxidation reaction repeated on the reexposed $\mathrm{PbO}$ surface [26]. The color of 


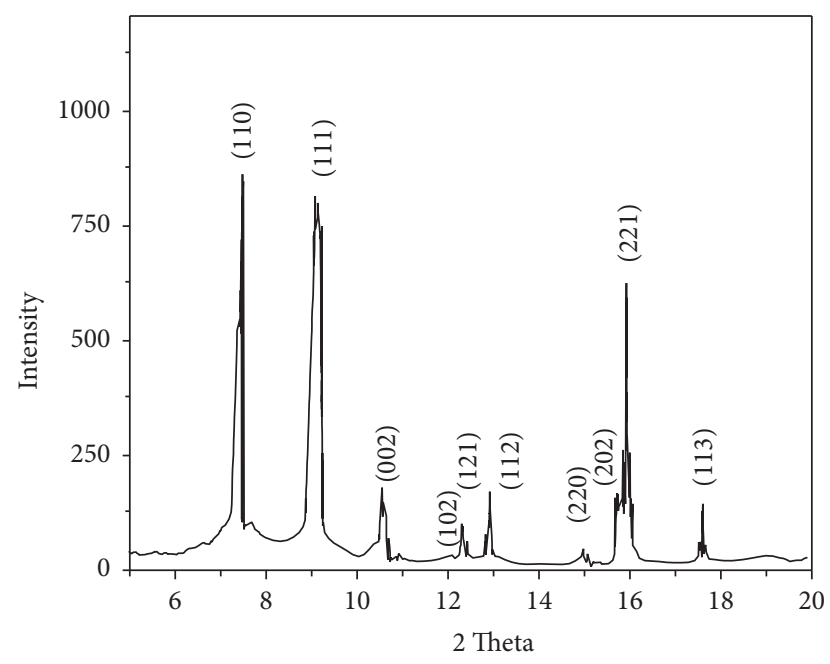

FIGURE 1: XRD pattern of synthesized $\mathrm{PbO}_{2}$ synthesized under $120^{\circ} \mathrm{C}$.

solution changed from original yellow to dark brown after the hydrothermal reaction. The reactive radicals were formed during the oxidation reaction and the specific mechanism steps are as follows:

$$
\begin{aligned}
& \left(\mathrm{NH}_{4}\right)_{2} \mathrm{~S}_{2} \mathrm{O}_{8}+2 \mathrm{H}_{2} \mathrm{O} \longrightarrow 2 \mathrm{HSO}_{4}{ }^{\circ}+2 \mathrm{NH}_{4} \mathrm{OH} \\
& \mathrm{HSO}_{4} \cdot \mathrm{H}_{2} \mathrm{O} \longrightarrow \mathrm{H}_{2} \mathrm{SO}_{4}+\mathrm{OH}^{\bullet} \\
& \mathrm{PbO}+\mathrm{OH}^{\cdot} \stackrel{\text { Hydrothermal }}{\longrightarrow} \mathrm{PbO}(\mathrm{OH}) \\
& \mathrm{PbO}(\mathrm{OH})+\mathrm{OH}^{\bullet} \stackrel{\text { Hydrothermal }}{\longrightarrow} \mathrm{PbO}(\mathrm{OH})_{2} \\
& \mathrm{PbO}(\mathrm{OH})_{2} \Longleftrightarrow \mathrm{PbO}_{2}+\mathrm{H}_{2} \mathrm{O}
\end{aligned}
$$

As can be seen from the XRD pattern of the as-prepared sample (Figure 1), the characteristic peaks of $\mathrm{PbO}_{2}$ appeared and almost no peak of $\mathrm{PbO}$ was observed. Therefore, it can be concluded that the conversion rate of $\mathrm{PbO}$ to $\mathrm{PbO}_{2}$ was close to $100 \%$. The peaks at $7.23^{\circ}, 9.05^{\circ}, 10.72^{\circ}, 12.05^{\circ}, 12.19^{\circ}, 12.97^{\circ}$, $15.01^{\circ}, 15.88^{\circ}, 16.03^{\circ}$, and $17.75^{\circ}$ are attributed to the (110), (111), (002), (102), (121), (112), (220), (202), and (221) planes of $\alpha$ $\mathrm{PbO}_{2}$. The preparation of $\mathrm{PbO}_{2}$ using $\beta-\mathrm{PbO}$ as precursor is highly effective.

For the sake of investigating the influence of temperature on the particle size of prepared $\mathrm{PbO}_{2}$, the hydrothermal reaction was performed at $100^{\circ} \mathrm{C}, 120^{\circ} \mathrm{C}, 140^{\circ} \mathrm{C}$, and $160^{\circ} \mathrm{C}$, respectively. On the basis of XRD spectra, the complete transformation of $\mathrm{PbO}$ can be achieved at $120^{\circ} \mathrm{C}, 140^{\circ} \mathrm{C}$, and $160^{\circ} \mathrm{C}$ as well. In contrast, only partial of $\mathrm{PbO}$ was converted to the $\mathrm{PbO}_{2}$ at $100^{\circ} \mathrm{C}$, possibly owing to the fact that the amount of formed $\mathrm{OH}^{\bullet}$ that owns the ability of converting $\mathrm{PbO}$ to $\mathrm{PbO}_{2}$ was extremely low [26]. The SEM images of as-prepared $\mathrm{PbO}_{2}$ at $120^{\circ} \mathrm{C}, 140^{\circ} \mathrm{C}$, and $160^{\circ} \mathrm{C}$ were shown in Figures 2(a)-2(c), respectively. It can be obviously seen that the particle size of $\mathrm{PbO}_{2}$ increased as the increasing temperature. The particles were in the 20 to $50 \mathrm{~nm}$ size range when the reaction was carried out at $120^{\circ} \mathrm{C}$, while in the 75 to $150 \mathrm{~nm}$ size range when the reaction was carried out at $160^{\circ} \mathrm{C}$. Finally, $120^{\circ} \mathrm{C}$ was chosen for all following experiments because the high demand of high specific surface area can be achieved by small particle size. The SEM image of the as-prepared nanocomposite of $\mathrm{PbO}_{2} / \mathrm{RGO}$ was shown in Figure 2(d). $\mathrm{PbO}_{2}$ was embedded uniformly in RGO sheets, indicating the successful preparation of $\mathrm{PbO}_{2} / \mathrm{RGO}$ nanocomposite.

Figure 3 showed the absorption spectra of X-GRL after certain degradation on the $\mathrm{PbO}_{2} / \mathrm{RGO} / \mathrm{ITO}$ electrode. For XGRL, a characteristic peak absorbance value at $530 \mathrm{~nm}$ in the visible region was observed. Besides, another two absorbance peaks at $240-250 \mathrm{~nm}$ and $280-290 \mathrm{~nm}$ in the ultraviolet region were also observed [27, 28]. The observed unique absorbance peaks can be attributed to azo linkage $(-\mathrm{N}=\mathrm{N}-)$ and benzene ring contained in X-GRL. The absorbance peak of azo bond $(-\mathrm{N}=\mathrm{N}-)$ that resulted from the $n \rightarrow \pi^{*}$ transition mainly appeared in the visible region. And the absorbance peak of benzene ring that resulted from the $\pi \rightarrow \pi^{*}$ transition mainly appeared in ultraviolet region $(240-250 \mathrm{~nm})$. As can be seen in Figure 3, with the occurrence of degradation reaction, the absorbency in the visible region decreased quickly and the absorbency in the ultraviolet region increased in contrast, suggesting the break of azo bond and the generation of many intermediate products with benzene ring. With the breakage of azo group, the absorbance at $240-250 \mathrm{~nm}$ also increased a little, while the absorbance at 280-290 nm was observed to decrease.

The relationship between the removal of color and COD of red X-GRL and reaction time using the $\mathrm{PbO}_{2} / \mathrm{RGO} / \mathrm{ITO}$ electrode was shown in Figure 4(a). The removal efficiency of color $(88.4 \%)$ was higher than that of COD (37.5\%), suggesting more chromophore structure of X-GRL was broken accompanied by the production of some acidic intermediates. The removal efficiencies of both color and COD showed an increase with increasing time and no obvious decrease trend was observed, suggesting the excellent stability of the $\mathrm{PbO}_{2} / \mathrm{RGO} / \mathrm{ITO}$ electrode. The average current efficiency (ACE) and energy consumption (EC) were also investigated and the calculation equations were as follows:

$$
\begin{aligned}
\mathrm{ACE} & =\frac{\left(\mathrm{COD}_{0}-\mathrm{COD}_{t}\right) F V}{8 I t} \times 100 \%, \\
\mathrm{EC} & =\frac{U I t}{3.6\left(\mathrm{COD}_{0}-\mathrm{COD}_{t}\right) V},
\end{aligned}
$$

where $\mathrm{COD}_{0}$ and $\mathrm{COD}_{t}$ are the chemical oxygen demand at initial time and given time $t\left(\mathrm{~g} \mathrm{O}_{2} / \mathrm{L}\right)$, respectively, $F$ is the Faraday constant $(96,487 \mathrm{C} / \mathrm{mol}), I$ is the current $(\mathrm{A}), t$ is the treatment time (s), $V$ is the volume of the solution (L), and $U$ is the voltage applied (V).

As shown in Figure 4(b), the ACE decreased while the EC increased linearly with the COD removal, which possibly was ascribed to the complexity of the formed intermediates. At the initial stage, the ACE was very high with the value of $99.1 \%$, and then decreased with the increasing COD removal. When the COD removal efficiency was higher than $20 \%$, the decrease of ACE became insignificant and the final obtained ACE value was 53.7\% after being treated for 240 min. The downward trend over time was similar to other 


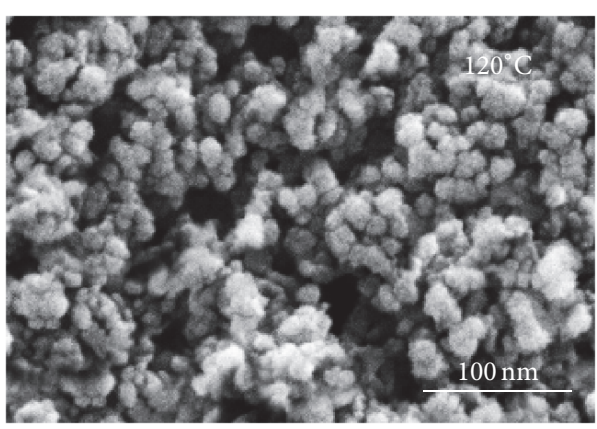

(a)

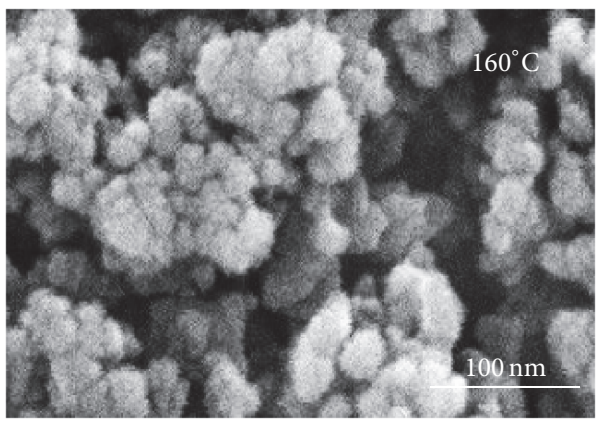

(c)

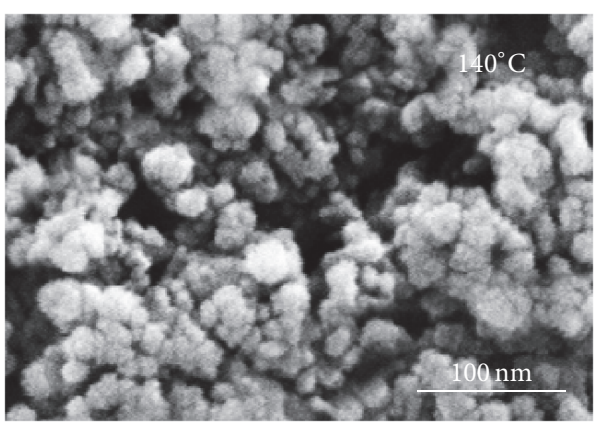

(b)

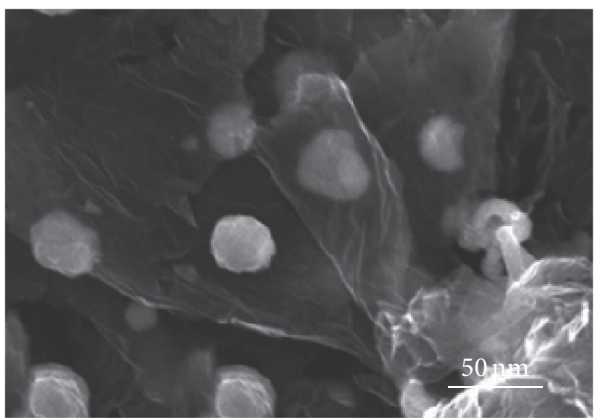

(d)

FIGURE 2: SEM images of $\mathrm{PbO}_{2}$ synthesized under (a) $120^{\circ} \mathrm{C}$, (b) $140^{\circ} \mathrm{C}$, and (c) $160^{\circ} \mathrm{C}$. (d) SEM image of the $\mathrm{PbO}_{2} / \mathrm{RGO}$ nanocomposite.

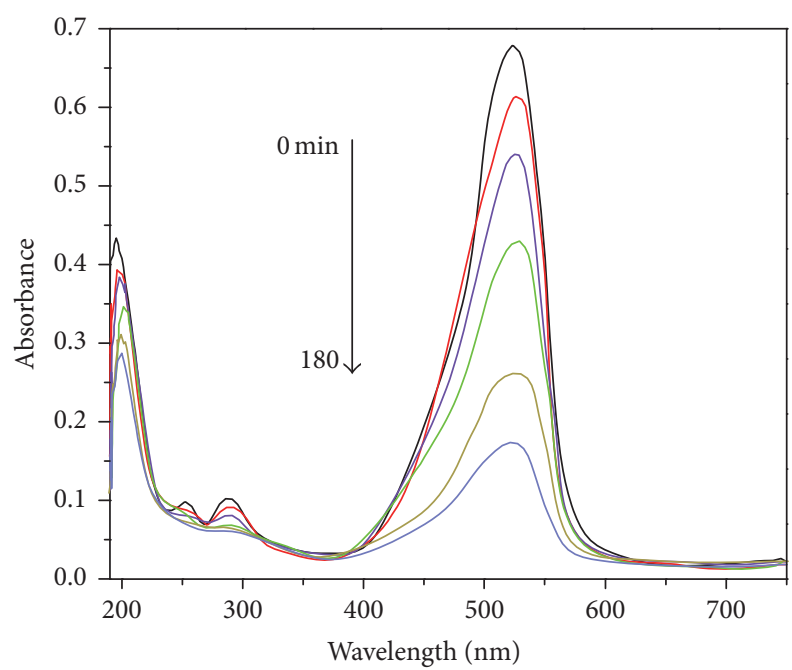

FIGURE 3: UV-vis spectra for cationic red X-GRL degradation by $\mathrm{PbO}_{2} / \mathrm{RGO} / \mathrm{ITO}$.

reports $[20,29]$ and the proposed explanation for the continuing decreasing ACE was the difficulty in the decomposition of generated organic acids. The current efficiency for the degradation of azo dye obtained in this study was higher than that reported in other works (less than 40\%) [18, 30], indicating the excellent performance of the proposed novel anode for the electrochemical oxidation of cationic red XGRL.
TABLE 1: The effect of current density on color and COD removal, ACE, and EC.

\begin{tabular}{lcccc}
\hline $\begin{array}{l}\text { Current } \\
\text { density } \\
\left(\mathrm{mA} / \mathrm{cm}^{2}\right)\end{array}$ & Color (\%) & COD (\%) & ACE (\%) & EC (kWh $\left./ \mathrm{kg}_{\mathrm{COD}}\right)$ \\
\hline 0.5 & 41.5 & 10.5 & 93.9 & 10.1 \\
1 & 61.6 & 19.4 & 59.8 & 27.1 \\
3 & 88.4 & 35.7 & 51.3 & 43.2 \\
\hline
\end{tabular}

The effects of current density on color removal, COD removal, $\mathrm{ACE}$ and $\mathrm{EC}$ were investigated and the results were shown in Table 1 . Obviously, the removal efficiencies of both color and COD were higher when higher current density applied, which was possibly ascribed to the increasing production rate of hydroxyl radical that decided the dye degradation with increasing current density. The removal efficiency of color (COD) was $43.3 \%(13.0 \%)$ and $87.1 \%(38.2 \%)$ at the applied current density of $0.8 \mathrm{~mA} / \mathrm{cm}^{2}$ and $4.8 \mathrm{~mA} / \mathrm{cm}^{2}$, respectively, indicating that current density is a very important parameter that affects the removal efficiency greatly. Nevertheless, the ACE showed a decrease with the increasing current density, demonstrating that the degradation was less efficient as the current density increased. When the degradation process took place for $120 \mathrm{~min}$, the ACE obtained was $93.9 \%$ and $51.3 \%$ at the current density of $0.5 \mathrm{~mA} / \mathrm{cm}^{2}$ and $3 \mathrm{~mA} / \mathrm{cm}^{2}$, respectively. The decrease of degradation efficiency was probably caused by the occurrence of side 


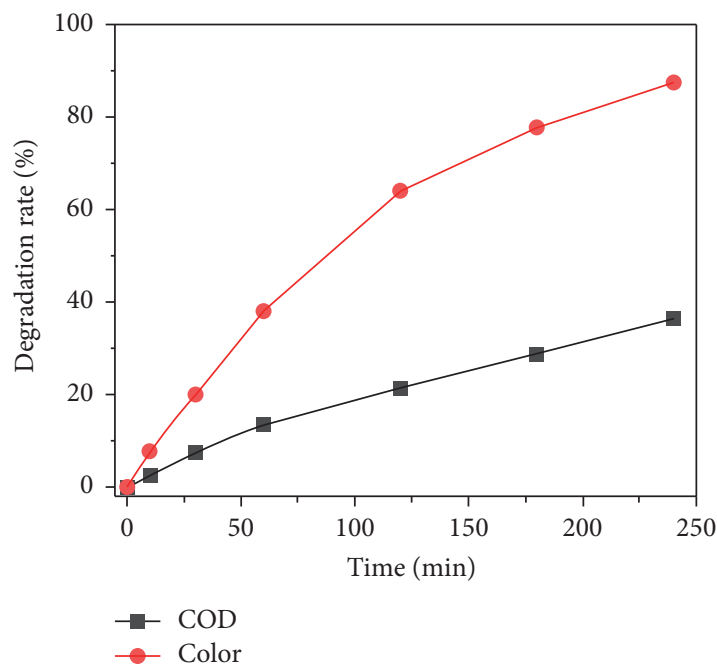

(a)

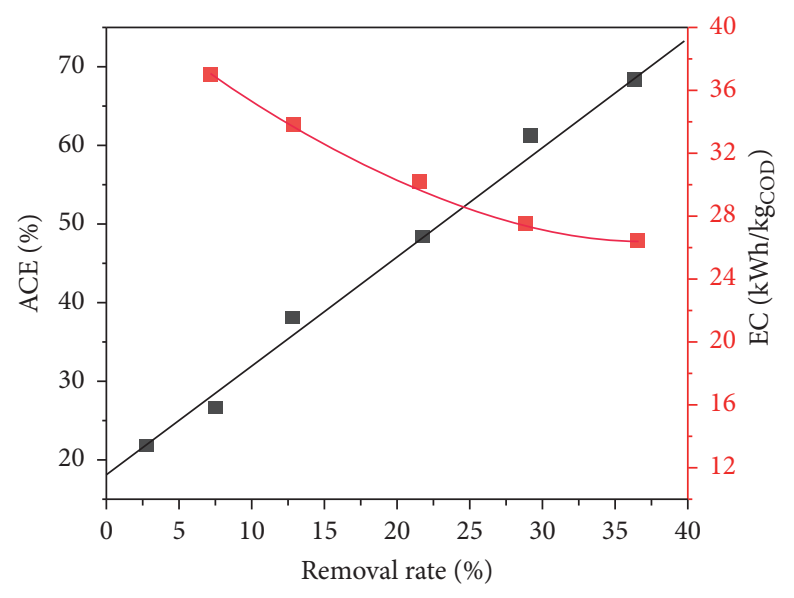

(b)

FIGURE 4: (a) Effect of degradation time on color removal and COD removal using $\mathrm{PbO}_{2} / \mathrm{RGO} / \mathrm{ITO}$. (b) Variation of ACE and EC with COD removal (pH: 5.0; cationic red X-GRL: $500 \mathrm{mg} / \mathrm{L}$; current density: $1.0 \mathrm{~mA} / \mathrm{cm}^{2} ; \mathrm{Na}_{2} \mathrm{SO}_{4}: 3 \mathrm{~g} / \mathrm{L} ; \mathrm{T}: 25^{\circ} \mathrm{C}$ ).

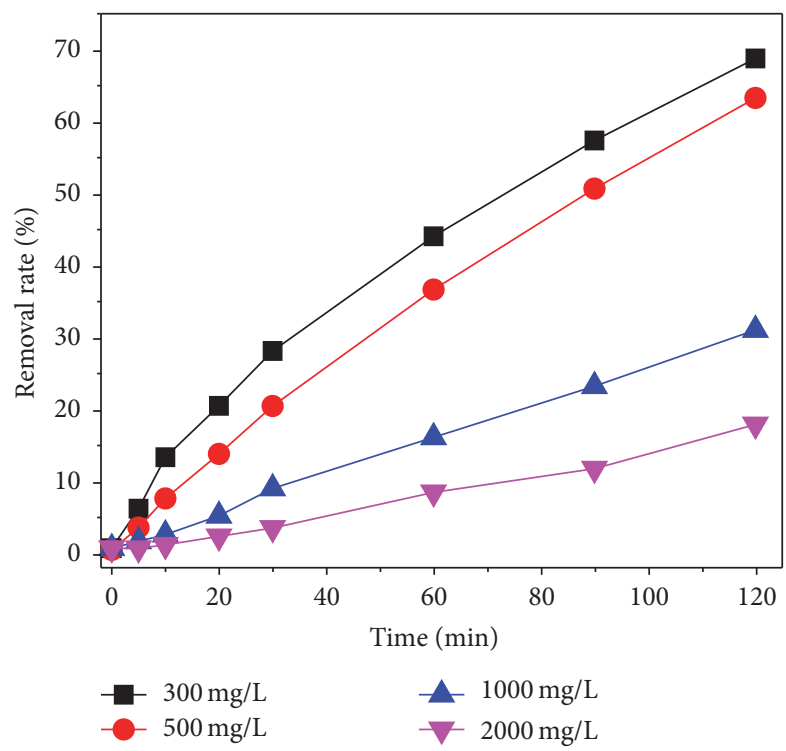

Figure 5: Effect of initial dye concentration on color and COD removal (pH: 5.0; $\mathrm{Na}_{2} \mathrm{SO}_{4}: 3 \mathrm{~g} / \mathrm{L}$; current density: $1.0 \mathrm{~mA} / \mathrm{cm}^{2} ; T$ : $\left.25^{\circ} \mathrm{C}\right)$.

reactions such as oxygen evolution at certain currents. In addition, the EC increased from 10.1 to $43.2 \mathrm{kWh} / \mathrm{kg}$ COD. Generally, long treatment time but less cost was required for the degradation process when low current density was used. In contrast, high current density employed will lead to short treatment time but costly. Therefore, for comprehensive consideration of current efficiency and removal efficiency, the current density of $1.0 \mathrm{~mA} / \mathrm{cm}^{2}$ would be the best choice, at which condition of the color removal, COD removal, and ACE would be relatively high and EC was acceptable.

The influence of initial concentration of X-GRL on the removal efficiency of color was also investigated and the results were shown in Figure 5. The removal efficiency of color was $69.3 \%$ within $120 \mathrm{~min}$ at the initial concentration of $300 \mathrm{mg} / \mathrm{L}$. However, the removal efficiency of color decreased to $16.7 \%$ as the initial concentration increased to $2000 \mathrm{mg} / \mathrm{L}$. The decrease of color removal possibly resulted from the decreasing ratio of formed hydroxyl radical to dye concentration. In addition, the absolute removal amount increased despite the decreased removal efficiency of color along with increasing initial concentration. The absolute removal amount of X-GRL increased from 209.1 to $361.7 \mathrm{mg} / \mathrm{L}$ as the initial concentration increased from 300 to $2000 \mathrm{mg} / \mathrm{L}$. Moreover, the ACE (EC) obtained at the initial concentration of $300 \mathrm{mg} / \mathrm{L}$ and $2000 \mathrm{mg} / \mathrm{L}$ were about $63.2 \%(29.4 \mathrm{kWh} / \mathrm{kg}$ COD) and $88.9 \%$ (18.5 kWh/kg COD), respectively. Though lower COD removal was observed with higher initial concentration, the COD removal can be enhanced with much more time. Besides, the ACE and EC changed little when the initial concentration varied in the range of $500-2000 \mathrm{mg} / \mathrm{L}$. As a result, the proposed technique in this study was also suitable for the degradation of dye wastewater with high concentration.

\section{Conclusions}

In our work, a simple hydrothermal method was employed for the preparation of $\mathrm{PbO}_{2}$ nanoparticles with $\beta$ - $\mathrm{PbO}$ as precursor and ammonium peroxydisulfate as oxidant. The size of as-prepared $\mathrm{PbO}_{2}$ nanoparticles was in the range of 20-50 nm. The $\mathrm{PbO}_{2} / \mathrm{RGO}$ nanocomposite was successfully prepared by incorporating $\mathrm{RGO}$ with $\mathrm{PbO}_{2}$. The fabricated $\mathrm{PbO}_{2} / \mathrm{RGO} / \mathrm{ITO}$ electrode can be applied for the electrocatalytic degradation of red X-GRL contained in wastewater. The degradation process is cost-effective but poorly effective with the applied low current density, while it is highly effective but costly with the applied high current density. The removal rate increased with the increasing temperature and the decreasing initial dye concentration as well. 


\section{Conflicts of Interest}

The authors declare that there are no conflicts of interest regarding the publication of this paper.

\section{Acknowledgments}

This work is supported by the National Natural Science Foundation of China (nos. 21207030 and 21207028) and Science Foundation of Zhejiang Province, China (nos. LY15B070013).

\section{References}

[1] G. Mishra and M. Tripathy, "A critical review of the treatments for decolourization of textile effluent," Colourage, vol. 40, pp. 35-35, 1993.

[2] Q. Dai, M. Zhou, and L. Lei, "Wet electrolytic oxidation of cationic red X-GRL," Journal of Hazardous Materials, vol. 137, no. 3, pp. 1870-1874, 2006.

[3] V. S. Mishra, V. V. Mahajani, and J. B. Joshi, "Wet air oxidation," Industrial and Engineering Chemistry Research, vol. 34, no. 1, pp. 2-48, 1995.

[4] L. Lei, X. Hu, G. Chen, J. F. Porter, and P. L. Yue, "Wet air oxidation of desizing wastewater from the textile industry," Industrial and Engineering Chemistry Research, vol. 39, no. 8, pp. 2896-2901, 2000.

[5] S. K. Bhargava, J. Tardio, J. Prasad, K. Föger, D. B. Akolekar, and S. C. Grocott, "Wet oxidation and catalytic wet oxidation," Industrial and Engineering Chemistry Research, vol. 45, no. 4, pp. 1221-1258, 2006.

[6] A. Eftaxias, J. Font, A. Fortuny, A. Fabregat, and F. Stüber, "Catalytic wet air oxidation of phenol over active carbon catalyst. Global kinetic modelling using simulated annealing," Applied Catalysis B: Environmental, vol. 67, no. 1-2, pp. 12-23, 2006.

[7] F. H. Oliveira, M. E. Osugi, F. M. Paschoal, D. Profeti, P. Olivi, and M. V. B. Zanoni, "Electrochemical oxidation of an acid dye by active chlorine generated using Ti/Sn $\mathrm{S}_{(1-x)} \mathrm{Ir}_{x} \mathrm{O}_{2}$ electrodes," Journal of Applied Electrochemistry, vol. 37, no. 5, pp. 583-592, 2007.

[8] J. A. Zazo, J. A. Casas, A. F. Mohedano, and J. J. Rodríguez, "Catalytic wet peroxide oxidation of phenol with a Fe/active carbon catalyst," Applied Catalysis B: Environmental, vol. 65, no. 3-4, pp. 261-268, 2006.

[9] K. Rajeshwar, J. G. Ibanez, and G. M. Swain, "Electrochemistry and the environment," Journal of Applied Electrochemistry, vol. 24, no. 11, pp. 1077-1091, 1994.

[10] C. Comninellis, "Electrocatalysis in the electrochemical conversion/combustion of organic pollutants for waste water treatment," Electrochimica Acta, vol. 39, no. 11-12, pp. 1857-1862, 1994.

[11] M. Zhou, Z. Wu, and D. Wang, "Electrocatalytic degradation of phenol in acidic and saline wastewater," Journal of Environmental Science and Health, Part A: Toxic/Hazardous Substances and Environmental Engineering, vol. 37, no. 7, pp. 1263-1275, 2002.

[12] R. Kötz, S. Stucki, and B. Carcer, "Electrochemical waste water treatment using high overvoltage anodes. Part I: physical and electrochemical properties of $\mathrm{SnO}_{2}$ anodes," Journal of Applied Electrochemistry, vol. 21, no. 1, pp. 14-20, 1991.
[13] P. Cañizares, F. Martınez, M. Diaz, J. Garcıa-Gómez, and M. A. Rodrigo, "Electrochemical oxidation of aqueous phenol wastes using active and nonactive electrodes," Journal of the Electrochemical Society, vol. 149, no. 8, pp. D118-D124, 2002.

[14] J. Jia, J. Yang, J. Liao, W. Wang, and Z. Wang, "Treatment of dyeing wastewater with ACF electrodes," Water Research, vol. 33, no. 3, pp. 881-884, 1999.

[15] M. A. Sanromán, M. Pazos, M. T. Ricart, and C. Cameselle, "Electrochemical decolourisation of structurally different dyes," Chemosphere, vol. 57, no. 3, pp. 233-239, 2004.

[16] H. S. Awad and N. A. Galwa, "Electrochemical degradation of Acid Blue and Basic Brown dyes on $\mathrm{Pb} / \mathrm{PbO}_{2}$ electrode in the presence of different conductive electrolyte and effect of various operating factors," Chemosphere, vol. 61, no. 9, pp. 1327-1335, 2005.

[17] N. Mohan and N. Balasubramanian, "In situ electrocatalytic oxidation of acid violet 12 dye effluent," Journal of Hazardous Materials, vol. 136, no. 2, pp. 239-243, 2006.

[18] N. Mohan, N. Balasubramanian, and V. Subramanian, "Electrochemical treatment of simulated textile effluent," Chemical Engineering and Technology, vol. 24, no. 7, pp. 749-753, 2001.

[19] X. Chen, G. Chen, and P. L. Yue, "Anodic oxidation of dyes at novel Ti/B-diamond electrodes," Chemical Engineering Science, vol. 58, no. 3-6, pp. 995-1001, 2003.

[20] A. Fernandes, A. Morao, M. Magrinho, A. Lopes, and I. Gonçalves, "Electrochemical degradation of C. I. Acid Orange 7," Dyes and Pigments, vol. 61, no. 3, pp. 287-296, 2004.

[21] L. Fu, D. Zhu, and A. Yu, "Galvanic replacement synthesis of silver dendrites-reduced graphene oxide composites and their surface-enhanced Raman scattering characteristics," Spectrochimica Acta Part A: Molecular and Biomolecular Spectroscopy, vol. 149, pp. 396-401, 2015.

[22] L. Fu, S. Yu, L. Thompson, and A. Yu, "Development of a novel nitrite electrochemical sensor by stepwise in situ formation of palladium and reduced graphene oxide nanocomposites," RSC Advances, vol. 5, no. 50, pp. 40111-40116, 2015.

[23] $\mathrm{L} . \mathrm{Fu}$ and $\mathrm{A}$. Yu, "Electroanalysis of dopamine using reduced graphene oxide-palladium nanocomposites," Nanoscience and Nanotechnology Letters, vol. 7, no. 2, pp. 147-151, 2015.

[24] A. Esfandiar, O. Akhavan, and A. Irajizad, "Melatonin as a powerful bio-antioxidant for reduction of graphene oxide," Journal of Materials Chemistry, vol. 21, no. 29, pp. 10907-10914, 2011.

[25] APHA, AWWA, and WEF, Standard Method for the Examination of Water and Wastewater, APHA, Washington, DC, USA, 19th edition, 1995.

[26] S. Ghasemi, M. F. Mousavi, M. Shamsipur, and H. Karami, "Sonochemical-assisted synthesis of nano-structured lead dioxide," Ultrasonics Sonochemistry, vol. 15, no. 4, pp. 448-455, 2008.

[27] Z. Ren, J. Guan, H. Gao, J. Tian, Y. Wen, and R. Zheng, "Characteristics of cationic Red X-GRL adsorption by raw diatomite and diatomite concentrate," Physicochemical Problems of Mineral Processing, vol. 52, no. 1, pp. 44-55, 2016.

[28] B. Qiu, X. Xu, H. Guo, Y. Dang, X. Cheng, and D. Sun, "Anaerobic transformation of Cationic Red X-GRL with low levels of carbon source," International Biodeterioration and Biodegradation, vol. 95, pp. 102-109, 2014. 
[29] M. Zhou, Q. Dai, L. Lei, C. Ma, and D. Wang, "Long life modified lead dioxide anode for organic wastewater treatment: electrochemical characteristics and degradation mechanism," Environmental Science \& Technology, vol. 39, no. 1, pp. 363-370, 2005.

[30] P. Cañizares, A. Gadri, J. Lobato et al., "Electrochemical oxidation of azoic dyes with conductive-diamond anodes," Industrial and Engineering Chemistry Research, vol. 45, no. 10, pp. 34683473, 2006. 

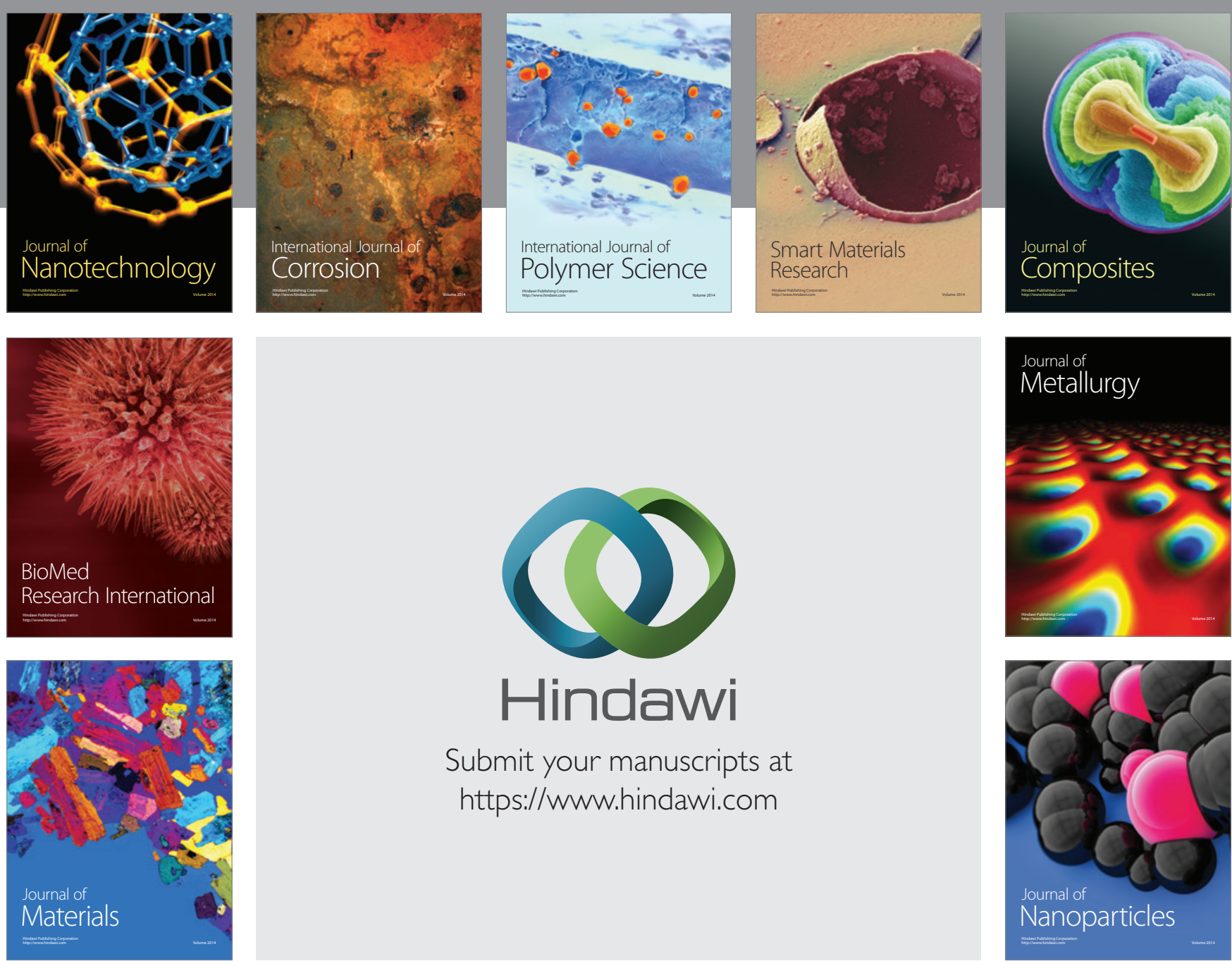

\section{Hindawi}

Submit your manuscripts at

https://www.hindawi.com

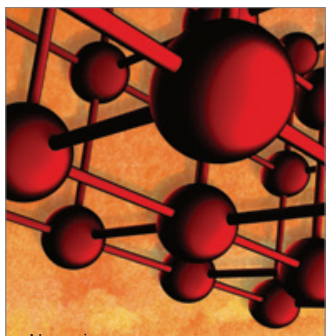

Materials Science and Engineering
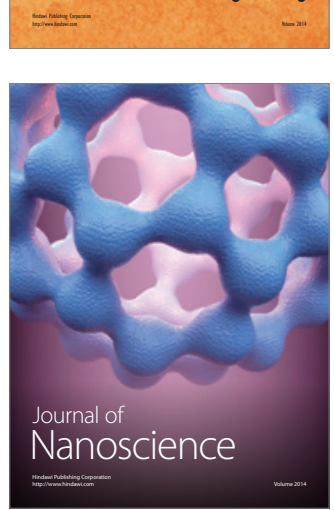
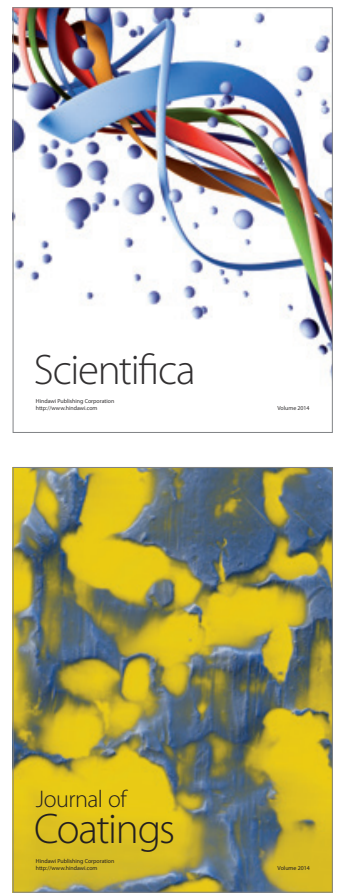
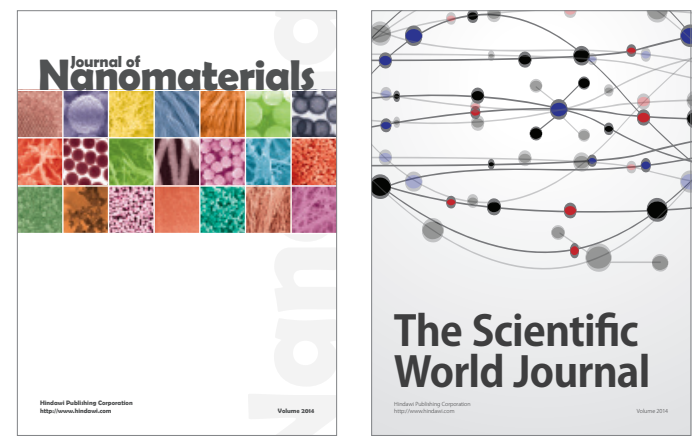

The Scientific World Journal
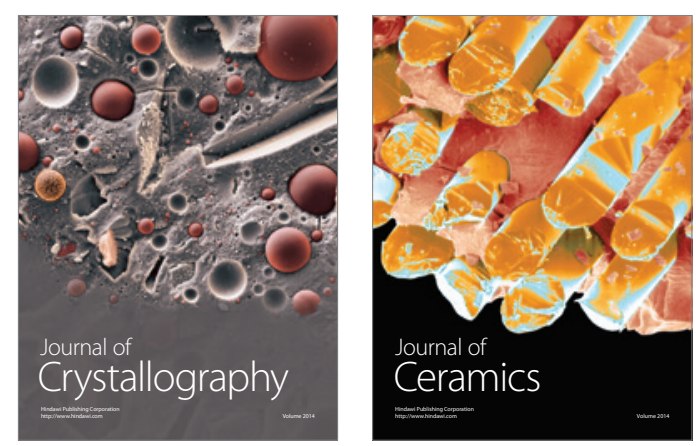
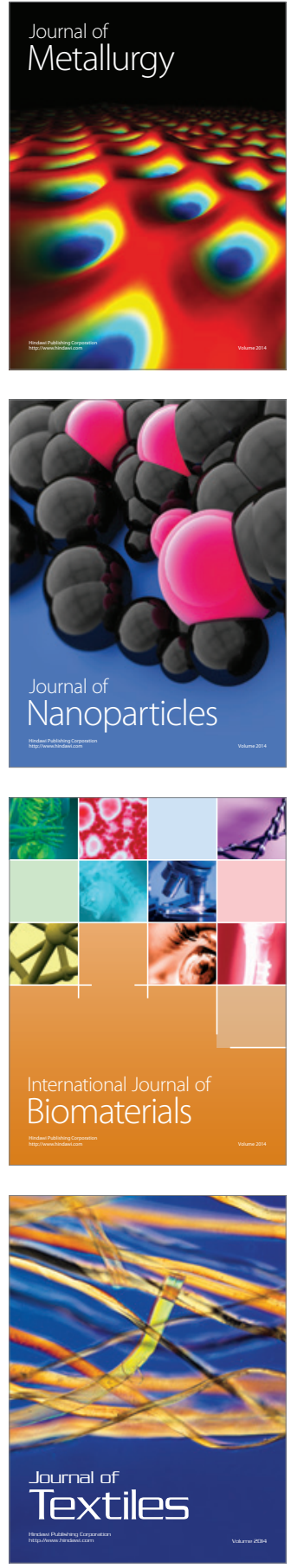